\title{
Polymer electrolytes based PAN for dye-sensitized solar cells
}

\author{
Mohammed Kadhim Jawad Alobaidi \\ Department of Physics, College of Science, University of Baghdad, Baghdad, Iraq \\ E-mail: mohamedkadhom@yahoo.com
}

\begin{abstract}
Solar cells has been assembly with electrolytes including $\mathrm{I}^{-} / \mathrm{I}_{3}^{-}$redox duality employ polyacrylonitrile (PAN), ethylene carbonate (EC), propylene carbonate (PC), with double iodide salts of tetrabutylammonium iodide (TBAI) and Lithium iodide (LiI) and iodine $\left(\mathrm{I}_{2}\right)$ were thoughtful for enhancing the efficiency of the solar cells. The rendering of the solar cells has been examining by alteration the weight ratio of the salts in the electrolyte. The solar cell with electrolyte comprises $\left(60 \%\right.$ wt. TBAI $/ 40 \%$ wt. LiI $\left.\left(+\mathrm{I}_{2}\right)\right)$ display elevated efficiency of $5.189 \%$ under $1000 \mathrm{~W} / \mathrm{m}^{2}$ light intensity. While the solar cell with electrolyte comprises $(60 \% \mathrm{wt}$. LiI $/ 40 \%$ wt. TBAI $\left.\left(+\mathrm{I}_{2}\right)\right)$ display a lower efficiency of $3.189 \%$. The conductivity raises with the raising TBAI salt weight ratio and attains the maximum value of $1.7 \times 10^{-3} \mathrm{~S} . \mathrm{cm}^{-1}$ at room temperature with $60 \%$ wt. TBAI, and the lower value of ionic conductivity of $5.27 \times 10^{-4} \mathrm{~S} . \mathrm{cm}^{-1}$ for electrolyte with $40 \%$ wt. TBAI. The results display that the conductivity rises with rising temperature. This may be attributed to the extending of the polymer and thereby output the free volume. The alteration in ionic conductivity with temperature obeys the Arrhenius type thermally activated process. The differences in activation energy mightily backup the alteration in the electrical conductivity.
\end{abstract}

\section{Key words}

Polymer electrolyte, double salts, Quasisolid- state dyesensitized solar cells.

\section{Article info.}

Received: Mar. 2017 Accepted: May. 2017 Published: Jun. 2017

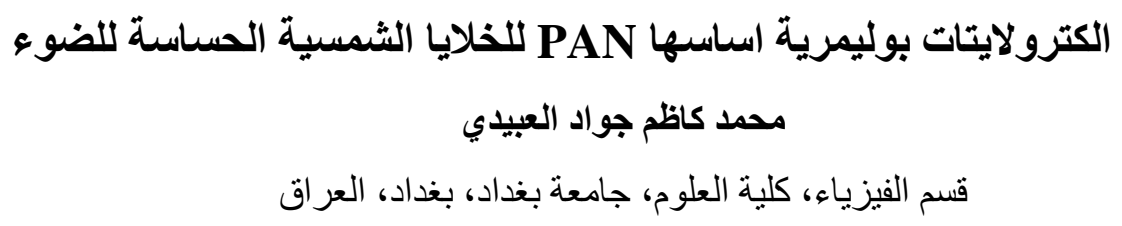

الخلاصة

تم تجميع خلايا شمسية مع الكترو لايتات تضم

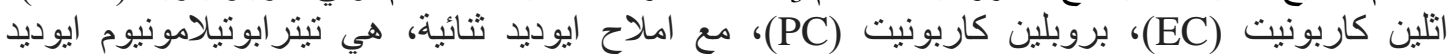

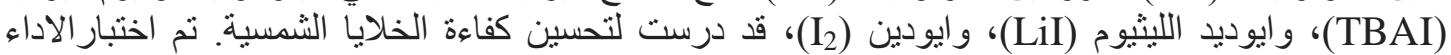
للخلايا الثمسية من خلال تغيير النسبة الوزنية للاملاح في الالكترو لات. اظهرت التهرت الخلية الثمسية مع الكترو لايت

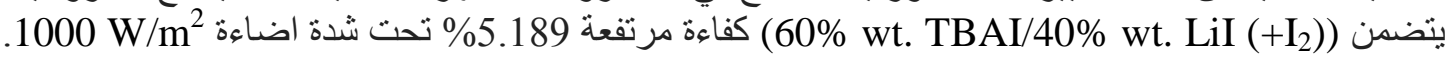
بينما ابدت الخلية الثمسية مع الكترو لايت يتضمن (60\% wt. LiI/40\% wt. TBAI (+I (4) كفاءة اقل

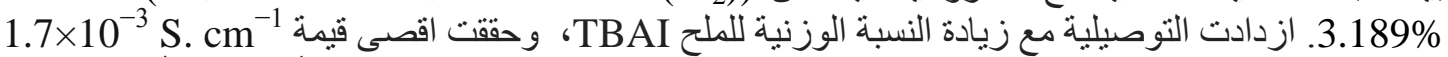

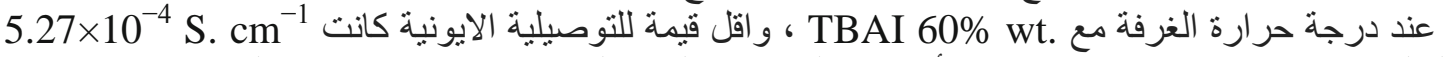

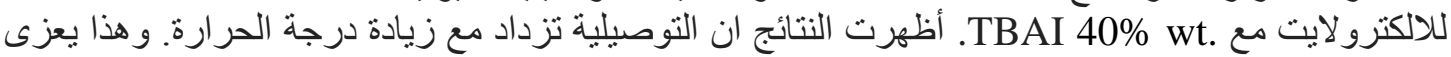

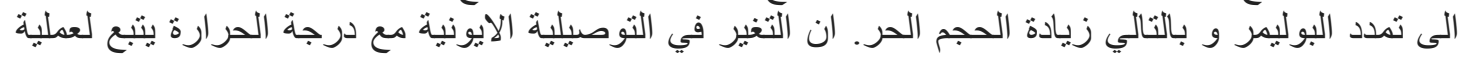

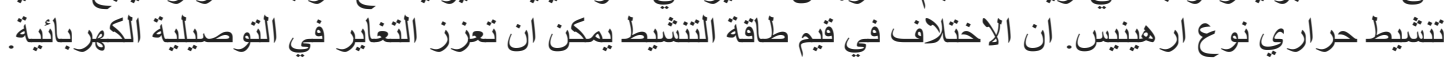

\section{Introduction}

The development of inexhaustible and clean energy sources is requisite to fulfill future energy needs without draining our petroleum and without contaminating our environment. 
Subsequently, the minimum setback, dye-sensitized solar cells (DSSCs) are come out as a reasonable alternative to accomplish future energy needs [1]. In general, the inclusive energy conversation efficiency of a cell, light to electricity, is affected by many agents, including the catalyst utilized in the counter electrode, the transmittance and the conductivity of the conducting substrate, the electrolyte installation, type of dye sensitizer, and distinctive of the $\mathrm{TiO}_{2}$ film. Evolution of gel polymer electrolytes with high iodide-ion conductivity is necessary to enhance the efficiency and lastly to fabricate commercially viable DSSCs since the iodide/triiodide redox couple has been the mostly used redox couple for DSSCs so far $[2,3]$. The nature of the cation in the iodide salt integrated with the host polymer matrix plays a significant role in the ion transport mechanism in DSSCs [4-6]. A photosensitizer should have a high absorption cross section at the wavelength convenient for the particular application and excellent photochemical and thermal stabilities. Other important parameters while inspect for or designing new photosensitizers include solubility and propensity to aggregate $[7,8]$. The aim of the work is to try to boost the efficiency of a DSSC based on gel electrolyte. By raising the amount of the short-circuit photocurrent $\left(\mathrm{J}_{\mathrm{sc}}\right)$ through raised iodide ion conductivity of electrolyte contain the best molar ratio of a double iodide (TBAI with a large cation and LiI with a small alkali cation as the other iodide salt).

\section{Experimental}

\section{Materials}

Poly (acrylonitrile) (PAN), tetrabutylammonium iodide (TBAI), lithium iodide (LiI), ethylene carbonate (EC), propylene carbonate (PC) and iodine chips $\left(\mathrm{I}_{2}\right)$, with purity more than $98 \%$, all purchased from SigmaAldrich, used as starting materials. N, N-dimethyl formamide (DMF) Obtained from Friedemann Schmidt Chemical used as a solvent.

\section{Preparation of electrolytes}

Polymer gel electrolytes assigned as (E1-E6) by solution cast technique prepared with double salts with different weight ratio. The salts (TBAI and LiI) resolved in $3 \mathrm{ml}$ of DMF solvent in a glass bottle by stirrer and heat to $65^{\circ} \mathrm{C}$. Then PAN was added up to the blend and stirred for $1 \mathrm{~h}$ till became a viscous gel-like solution was formed. Then the blend was left about to cool down, then iodine $\mathrm{I}_{2}$ chips (10 $\%$ weight of salts) was also added. Finally, the blend was again continuously magnetically stirred $(24 \mathrm{~h})$ to obtain a homogeneous electrolyte. The electrolytes were prepared and thoughtful under controlled temperature and humidity conditions $\left(25^{\circ} \mathrm{C}\right.$ and $\left.\mathrm{RH} 50 \%\right)$. The weights of PAN, EC, and PC were kept at $0.12 \mathrm{~g}, \quad 0.38 \mathrm{~g}$, and $0.38 \mathrm{~g}$ respectively. This step was repeated for all weight ratio as shown in Table 1.

Table 1: Weight ratio of TBAI and LiI used to prepare polymer electrolytes.

\begin{tabular}{|c|c|c|c|c|}
\hline Electrolyte & TBAI \% (W/W) & $\mathrm{LiI} \%(\mathrm{~W} / \mathrm{W})$ & TBAI $(\mathrm{g})$ & $\mathrm{LiI}(\mathrm{g})$ \\
\hline E1 & 70 & 30 & 0.110 & 0 \\
\hline E2 & 65 & 35 & 0.088 & 0.022 \\
\hline E3 & 60 & 40 & 0.066 & 0.044 \\
\hline E4 & 55 & 45 & 0.044 & 0.066 \\
\hline E5 & 50 & 50 & 0.022 & 0.088 \\
\hline E6 & 40 & 60 & 0 & 0.110 \\
\hline
\end{tabular}




\section{Conductivity measurements}

An Ac bridge HIOKI LCR $3520 \mathrm{Hi}$ TESTER with frequency ranging between $50 \mathrm{~Hz}$ and $5 \mathrm{MHz}$ was used for impedance measurements. The sample was placed in a poly(tetrafluoroethylene) spacer ring compressed between two stainless steel electrodes and sealed in a testing cell. The temperature of the sample was varied from $\left(25-100{ }^{\circ} \mathrm{C}\right)$ at $10{ }^{\circ} \mathrm{C}$ intervals.

\section{Photovoltaic fabrication}

Nanoporous Titanium dioxide $\mathrm{TiO}_{2}$ layer formed on FTO glass. $\mathrm{TiO}_{2}$ powder about $0.2 \mathrm{~g}$ was grounded well in an agate mortar than $0.14 \mathrm{~g}$ of glacial acetic acid was added. About $0.1 \mathrm{~g}$ of Carbowax and one drop of Triton X 100 add and mix well, $2 \mathrm{ml}$ of ethanol were mixed to form a paste. The colloidal suspension was cast using a doctor blade method for obtaining a porous layer after sintering at $\sim 450{ }^{\circ} \mathrm{C}$ for $25 \mathrm{~min}$. $\mathrm{TiO}_{2}$ coated electrodes soaked in an ethanol solution of dye sensitizer ruthenium 535-bis TBA (N3 dye) for $24 \mathrm{~h}$. The counter electrode has been ready by the thermal method, an alcoholic solution of platinum salt $\left(\mathrm{H}_{2} \mathrm{PtCl}_{6}\right)$ is spread on FTO substrate and after the solvent evaporation, the FTO substrate is fired in an oven in $400{ }^{\circ} \mathrm{C}$ for $\sim 25$ min. The DSSC prepared by sandwiching the gel electrolyte between the photoanode and platinum counter electrode. The J-V characteristics of the DSSC have measured with a Keithley 2400 source meter under 1000 W. $\mathrm{cm}^{-2}$ illumination.

\section{Results and discussion}

\section{Ionic conductivity}

Fig. 1 shows the ionic conductivity of the polymer electrolytes at various temperatures for with different amounts of TBAI /LiI. It can be an offer that the conductivity increases with the increase in TBAI salt weight ratio and reaches the highest value of $1.737 \times 10^{-3}{\mathrm{~S} . ~ \mathrm{~cm}^{-1}}^{-1} 298 \mathrm{~K}$ for $60 \%$ of TBAI content, beyond decreases on more additional of TBAI. At a low concentration of TBAI, the conductivity is low due to the low number of charge carriers in the electrolytes. Nevertheless, with an increase in TBAI (60\% wt.) the ionic conductivity increases as a result of the buildup of charge carriers $[9,10]$. The TBAI may coordinate with the iodide ions, which boost the charge transport of iodide ions in the electrolytes. The ionic conductivity further decreased on addition of TBAI, which may be due to the buildup of charge carriers in offset by the restraint effect of ionic clouds and the forming of neutral ion aggregates that do not participate to the ionic conduction [10]. The change in ionic conductivity is studied on temperature and the results obtained are shown in a temperature dependent Arrhenius plot (Fig. 1). It is clear that the conductivity increases with increasing temperature which may be imputed to the expansion of the polymer and thereby output the free volume. Thus the ions, solvated molecules, or polymer segments can move to free volume and hence increase the conductivity. The ionic conductivities were evaluated using the relation:

$\sigma=\frac{l}{R_{b} A}$

where $l$ is the thickness, $R_{\mathrm{b}}$ is the bulk resistance and $A$ is the contact area of the electrolyte film during the experiment. The poly(acrylonitrile) was attributed to the cooperation of ionic conduction of $\mathrm{I}^{-} / \mathrm{I}_{3}^{-}$ions. It has been notifying that the increase in conductivity is favorable for the refinement of energy conversion efficiency [9]. 


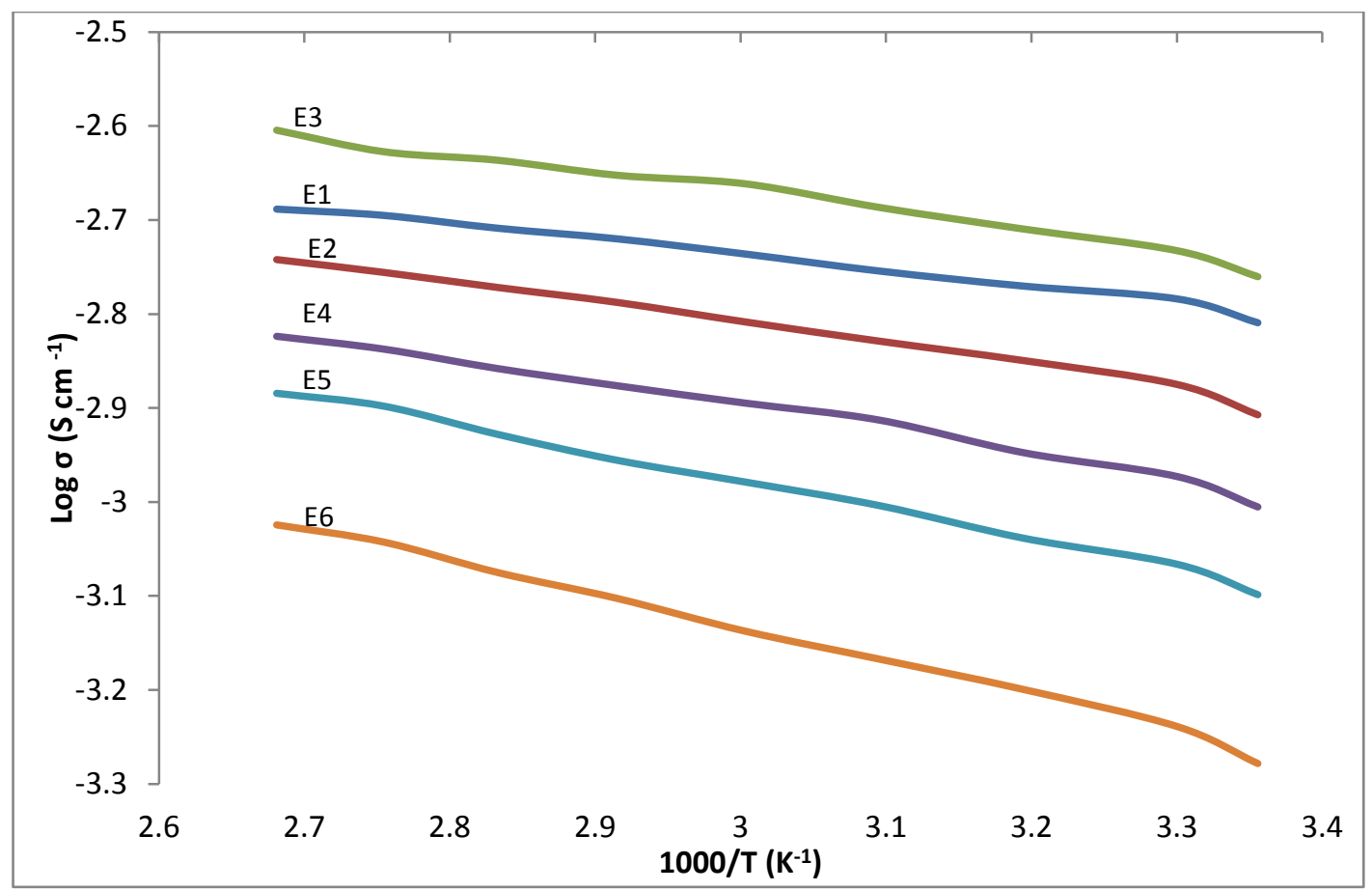

Fig.1: The alteration of conductivity plot vs the reciprocal temperature for different electrolytes compositions.

The ionic conductivity of a polymer electrolyte relies on the focus of carriers and their mobility, the conductivity of electrolytes increases with temperature owing to the higher segmental movement of the polymer chain in the amorphous phase. The temperature reliance of conductivity of the polymer electrolytes is following by an Arrhenius Eq. (2) [11]:

$\sigma=\sigma_{0} \exp -{ }_{K T}^{E_{a}}$

The addendum of plasticizers to a particular amount raises the polymer chain resilience and raising the motion of ion transport. The chain resilience of the PAN spine promote the mobility and hence the ionic conductivity. That can be assigned to the capability of plasticizer to permeate the polymer matrix foundation an attractive force on account of cohesive forces between the polymer chains is minimize. Such simplify an improvement in the segmental movements of PAN chains by reduction the $T_{g}$ and hence increases the ionic conductivity [12]. Also, the conductivity rises with raising the temperature and reach the optimum value $2.486 \times 10^{-3} \mathrm{~S} \mathrm{~cm}^{-1}$ at $373 \mathrm{~K}$ as a display in Fig. 2. That possibly comprehend with the confirmation that as the temperature rises, the vibrational energy of segmental movement works against the hydrostatic pressure enjoined by its adjoining atoms. Subsequently, it outputs a little quantity of space encirclement its size in which vibrational movement can occur. Thus, free volume about the polymer chain brings about to raise in mobility of ions and then raising the conductivity. Also is related to reducing in viscosity, therefore, rising in chain pliancy [13]. When the temperature rises, the hydrogen ions leap into adjoining vacant sites and, hence, ionic conductivity promotes the change in activation energy hardly supports the change in the conductivity. PAN-based polymer electrolytes are shaped mainly by trapping the EC/PC based electrolytic solution be shaped by PAN. 


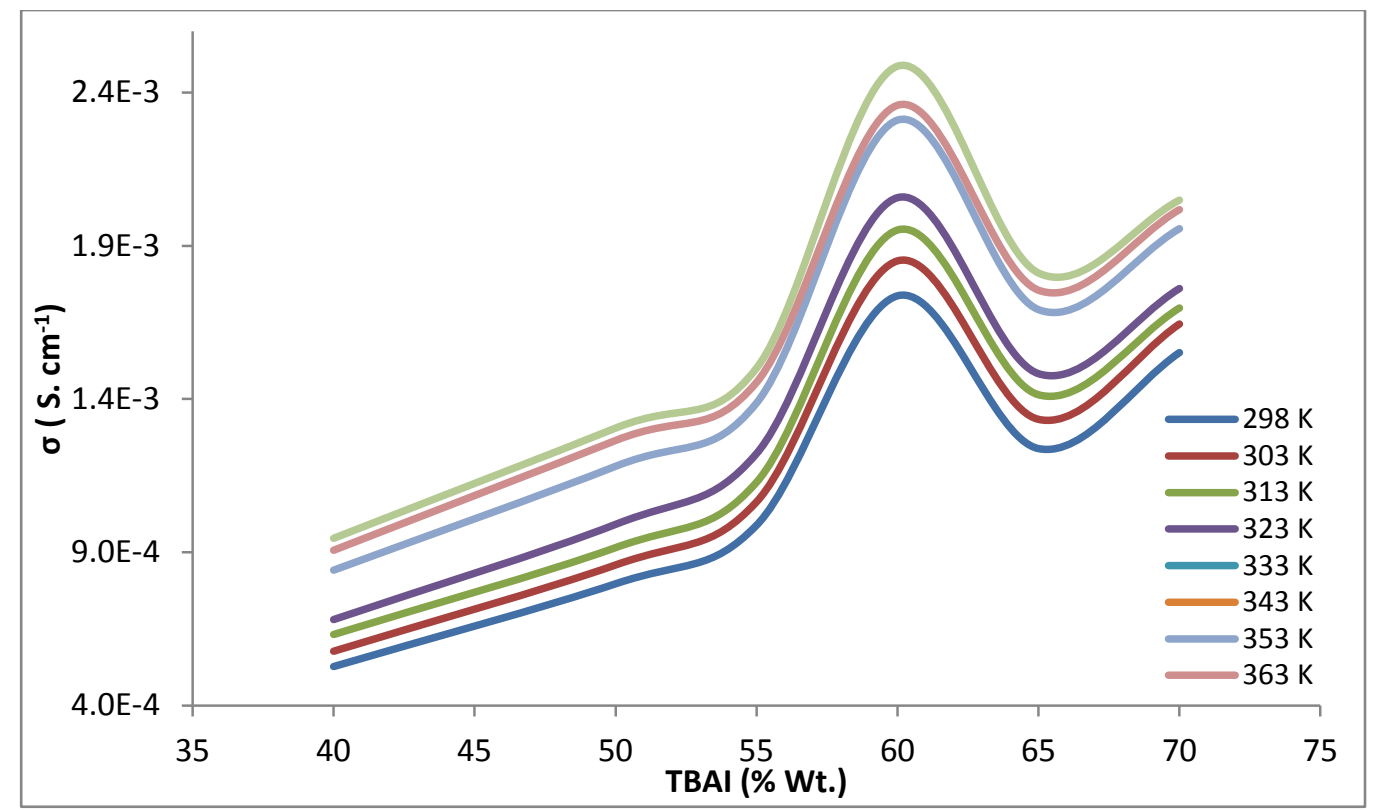

Fig. 2: Dependence of ionic conductivity on TBAI weight ratio for the gel polymer electrolytes.

The dielectric constant of $\mathrm{PC}$ is high which used as a solvent with low molecular weight. However, the high dielectric constant favors salt dissociation, the high ionic mobility in the electrolytic solution which created by resolving the two salts in the EC/PC co-solvent result from the low viscosity $[14,15]$. The activation energy values, which correspond to the Arrhenius plot, are nearly constant for all electrolyte samples studied and independent of the salt weight ratios
(TBAI/LiI). The computed activation energies $\left(E_{a}\right)$ of polymer electrolytes are given in Table 2. The activation energy is highly independent of the salt weight ratio (low or temperate) and the type of salt used but depends basically only on the type of solvent, in particular on the nature of the solvent hetero atom. The dependence of the ionic conductivity of the polymer electrolytes on salt weight ratio is comparable to that reported by others [16].

Table 2: Conductivity at ambient temperature and activation energy $\left(E_{a}\right)$ of different polymer electrolytes

\begin{tabular}{|c|c|c|}
\hline Electrolyte & $\sigma\left(\mathbf{S . ~}_{\mathbf{~ c m}}{ }^{-\mathbf{1}}\right)$ & $\mathbf{E}_{\mathbf{a}(\mathbf{e V})}$ \\
\hline E1 & 0.001551 & 0.0149 \\
\hline E2 & 0.001238 & 0.0199 \\
\hline E3 & 0.001737 & 0.0184 \\
\hline E4 & 0.000988 & 0.0222 \\
\hline E5 & 0.000797 & 0.0268 \\
\hline E6 & 0.000527 & 0.0315 \\
\hline
\end{tabular}

Their results show that the ion transport in these systems involves a single activated process, which depends on the solvent functional group. This activation process is very likely the dipole re-orientation which depends on the dipole relaxation rates. The elevated electrical conductivity result from the lower $E_{a}$ value [10]. It is notified that the minimum activation energy is the properties advantage of the best conductivity value [13]. 
2. Photovoltaic performance of DSSC

The photoelectrochemical characteristics of DSSCs have been investigated by studied the effect of ionic conductivity on the efficiency of a set of cells fabricated by sandwiching the several polymer gel electrolytes. The photovoltaic parameters like shortcircuit current density $\left(\mathrm{J}_{\mathrm{sc}}\right)$, open circuit voltage $\left(\mathrm{V}_{\mathrm{oc}}\right)$, fill factor $(\mathrm{FF})$, and energy conversion efficiency $(\eta)$ were display in Table $3 . \mathrm{J}_{\mathrm{SC}}$ and $\mathrm{V}_{\mathrm{oc}}$ enhance with raises in the TBAI weight ratio up to $60 \%$. The change in $\mathrm{J}_{\mathrm{SC}}$ is on account of the adjusted ionic conductivity of the polymer electrolytes. The $\mathrm{J}_{\mathrm{sc}}$ results are in superb agreement with the conductivity data.

Table 3: Photovoltaic Parameters of the fabricated cells contain six different polymer electrolytes.

\begin{tabular}{|c|c|c|c|c|c|c|}
\hline Electrolyte & $\begin{array}{c}\text { TBAI } \\
\%\end{array}$ & $\begin{array}{c}\mathrm{LiI} \\
\%\end{array}$ & $\begin{array}{c}\mathrm{J}_{\mathrm{sc}} \\
\left(\mathrm{mA} / \mathrm{cm}^{2}\right)\end{array}$ & $\begin{array}{c}\mathrm{V}_{\text {oc }} \\
(\mathrm{volt})\end{array}$ & $\mathrm{FF}$ & $\begin{array}{c}\eta \\
\%\end{array}$ \\
\hline $\mathrm{E} 1$ & 70 & 30 & 10.26 & 0.615 & 0.635 & 4.28 \\
\hline $\mathrm{E} 2$ & 65 & 35 & 10.26 & 0.645 & 0.681 & 4.50 \\
\hline E3 & 60 & 40 & 11.15 & 0.680 & 0.684 & 5.18 \\
\hline E4 & 55 & 45 & 9.46 & 0.610 & 0.682 & 3.87 \\
\hline E5 & 50 & 50 & 8.69 & 0.570 & 0.711 & 3.52 \\
\hline E6 & 40 & 60 & 9.83 & 0.636 & 0.510 & 3.19 \\
\hline
\end{tabular}

Fig. 3 shows the current densityvoltage $(\mathrm{J}-\mathrm{V})$ curves of the cells fabricated including electrolytes, under illuminated conditions (AM 1.5, 1000 $\mathrm{W} \mathrm{m}^{-2}$ ). It was notified that the adsorption of cations such as $\mathrm{Li}^{+}, \mathrm{Na}^{+}$, $\mathrm{TBA}^{+}$and $\mathrm{Mg}^{2+}$ into a polycrystalline $\mathrm{TiO}_{2}$ electrode are significant not only in fixing the flat band potential of the electrode but also in the designation of electron diffusion coefficients of the mesoporous electrodes. The lithium salt could screen the field caused by space charge created under illumination of the heterojunction leading to inhibition of charge recombination and then to the increase of photo-generated electron on $\mathrm{TiO}_{2}$ [17]. The varied short circuit current density is because of the enhanced ionic conductivity of the polymer electrolytes. The better penetrating property and higher ionic conductivity of the electrolytes result in the higher FF value [9]. The spread coefficients of electrons in mesoporous $\mathrm{TiO}_{2}$ systems increment with the rise of cation density on nanocrystalline $\mathrm{TiO}_{2}$ in the order of $\mathrm{TBA}^{+}<\mathrm{Na}^{+}<\mathrm{Li}^{+}[16]$, the efficiency alteration follows essentially the same alteration as $\mathrm{J}_{\mathrm{sc}}$. The solar cell fabricated with the double iodide with $(60 \%$ wt. TBAI/40\% wt. LiI) has demonstrated the highest energy conversion efficiency of $5.186 \%$ while the solar cells fabricated with the electrolyte with $(60 \%$ wt. LiI/40\% wt. TBAI) have display efficiencies of $3.189 \%$. The use of the binary iodide mixture has clearly enhanced the solar cell efficiency. 


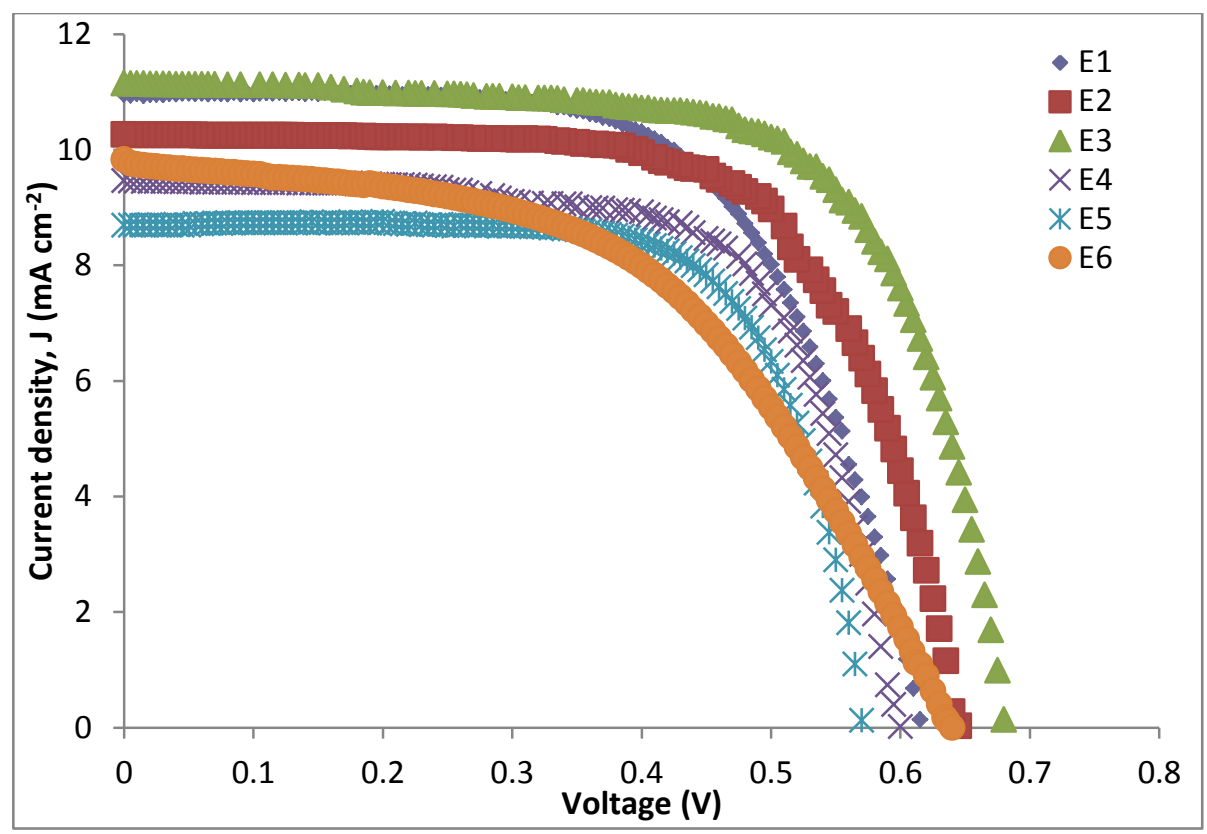

Fig. 3: The current density-photovoltage $(\mathrm{J}-\mathrm{V})$ of solar cells of arrangement Glass/FTO/TiO $/$ /Dye/electrolyte/Pt/FTO/glass.

The drop in $\mathrm{V}_{\text {oc }}$ is higher for the $\mathrm{Li}^{+}$ ions because of a bigger descending shift of the conduction band edge motivated by the adsorption of $\mathrm{Li}^{+}$ cations on the surface of nano-titania grains. Little radius cations such as $\mathrm{Li}^{+}$ and $\mathrm{K}^{+}$can insertion into the lattice of nano $\mathrm{TiO}_{2}$ causing a positive shift in the conduction band edge potential. This procedure raising the driving force for charge injection and normally leads to a higher $\mathbf{J}_{\mathrm{sc}}$ at the expense of $\mathrm{V}_{\mathrm{oc}}[14]$.

\section{Conclusions}

In this paper, the effect of double iodide system polymer electrolytes with various weight ratios of TBAI/LiI salts were prepared. The impact of TBAI on ionic conductivity of polymer electrolytes was thoughtful utilizing EIS measurements. The high ionic conductivity of $1.7 \times 10^{-3} \mathrm{~S} \mathrm{~cm}^{-1}$ was gotten for the $(60 \%$ wt. TBAI/ $40 \%$ LiI) polymer electrolytes. It is observed that the minimum activation energy is the properties feature of the best conductivity value. The best performance of photovoltaic characteristics obtained for DSSCs fabricated using $(60 \%$ wt. TBAI $/ 40 \%$ LiI) added polymer electrolytes with $\mathrm{V}_{\mathrm{oc}}$ of $0.68 \mathrm{~V}, \mathrm{~J}_{\mathrm{sc}}$ of $11.15 \mathrm{~mA} \mathrm{~cm}{ }^{-2}$, FF of 0.684 , and overall conversion efficiency of $5.186 \%$.

\section{References}

[1] G. Xue, Y. Guo, T. Yu, J. Guan, X. Yu, J. Zhang, J. Liu, Z. Zou, Int. J. Electrochem. Sci., 7 (2012) 14961511.

[2] S. Lua, R. Koeppea, S. Gunes, N. S. Sariciftci, Solar Energy Materials \& Solar Cells, 91 (2007) 1081-1086.

[3] M. K. Jawad, E.A.Al-Ajaj, M. H. Suhail, S.R. Majid, Advances in Physics Theories and Applications, 34 (2014) 51-59.

[4] T. M. W. J. Bandara, M. A. K. L. Dissanayake, W. J. M. J. S. R. Jayasundara, I. Albinssone, B. E. Mellander, Phys. Chem. Chem. Phys., 14 (2012) 8620-8627.

[5] G. W. Park, C. G. Hwang, J. W. Jung, Y. M. Jung, Bull. Korean Chem. Soc., 33, 12, (2012) 4093-4097.

[6] T. H. Tsai, S. C. Chiou, S. M. Chen, K. C. Lin, Int. J. Electrochem. Sci., 6 (2012) 3938-3950. 
[7] G. Liu, A. Klein, A. Thissen, W. Jaegermann, Surface Science, 539 (2003) 37-48.

[8] S. Senthilarasu, S. Velumani, R. Sathyamoorthy, A. Subbarayan, J. A. Ascencio, G. Canizal, P. J. Sebastian, J. A. Chavez, R. Perez, Appl. Phys. A, 77 (2003) 383-389.

[9] V. M. Mohan and K. Murakami, Journal of Advanced Research in Physics, 2, 2 (2011) 1-6.

[10] J. Theerthagiri, R. A. Senthi, M. H. Buraidah, J. Madhavan, A. K. Arof, Ionics, 21, 10 (2015) 28892896.

[11] C.-W. Kuo, C.-W. Huang, B.-K. Chen, W.-B. Li, P.-R. Chen, T.-H. Ho, C.-G. Tseng, T.-Y. Wu, (2013), Int. J. Electrochem. Sci., 8 (2013) 38343850.

[12] G.K. Prajapati, R. Roshan, P.N. Gupta, Journal of Physics and Chemistry of Solids, 71 (2010) 17171723.
[13] M.F. Shukur, R. Ithnin, H.A. Illias, M.F.Z. Kadir, Optical Materials, 35 (2013) 1834-1841.

[14] M.A.K.L. Dissanayake, C.A. Thotawatthage, G.K.R. Senadeera, T.M.W.J. Bandara, W.J.M.J.S.R. Jayasundera, B.-E. Mellander, Journal of Photochemistry and Photobiology A: Chemistry, 246 (2012) 29-35.

[15] M. K. Jawad, S.R. Majid, E.A.AlAjaj, M. H. Suhail, Advances in Physics Theories and Applications, 29 (2014) 14-22.

[16] J. Kang, W. LI, X. Wang, Y. Lin, X. Li, X. Xiao, S. Fang, Journal of Applied Electrochemistry, 34 (2004) 301-304.

[17] G. K. R. Senadeera and N. de Silva, Sri Lankan Journal of Physics, 7 (2006) 15-22. 